7-21-2017

\title{
A Comparative Analysis of Translesion DNA Synthesis Catalyzed by a High-Fidelity DNA Polymerase
}

\author{
Anvesh Dasari \\ Cleveland State University \\ Tejal Deodhar \\ Cleveland State University \\ Anthony J. Berdis \\ Cleveland State University, A.BERDIS@csuohio.edu
}

Follow this and additional works at: https://engagedscholarship.csuohio.edu/scichem_facpub

Part of the Biochemistry Commons, and the Medical Molecular Biology Commons

How does access to this work benefit you? Let us know!

\section{Recommended Citation}

Dasari, Anvesh; Deodhar, Tejal; and Berdis, Anthony J., "A Comparative Analysis of Translesion DNA Synthesis Catalyzed by a High-Fidelity DNA Polymerase" (2017). Chemistry Faculty Publications. 520. https://engagedscholarship.csuohio.edu/scichem_facpub/520

This Article is brought to you for free and open access by the Chemistry Department at EngagedScholarship@CSU. It has been accepted for inclusion in Chemistry Faculty Publications by an authorized administrator of EngagedScholarship@CSU. For more information, please contact library.es@csuohio.edu. 


\title{
A Comparative Analysis of Translesion DNA Synthesis Catalyzed by a High- Fidelity DNA Polymerase
}

\author{
Anvesh Dasari, Tejal Deodhar, and Anthony J. Berdis
}

\begin{abstract}
Translesion DNA synthesis (TLS) is the ability of DNA polymerases to incorporate nucleotides opposite and beyond damaged DNA. TLS activity is an important risk factor for the initiation and progression of genetic diseases such as cancer. In this study, we evaluate the ability of a high-fidelity DNA polymerase to perform TLS with 8-oxo-guanine (8-oxo-G), a highly pro-mutagenic DNA lesion formed by reactive oxygen species. Results of kinetic studies monitoring the incorporation of modified nucleotide analogs demonstrate that the binding affinity of the incoming dNTP is controlled by the overall hydrophobicity of the nucleobase. However, the rate constant for the polymerization step is regulated by hydrogen-bonding interactions made between the incoming nucleotide with 8-oxo-G. Results generated here for replicating the miscoding 8-oxo-G are compared to those published for the replication of the non-instructional abasic site. During the replication of both lesions, binding of the nucleotide substrate is controlled by energetics associated with nucleobase desolvation, whereas the rate constant for the polymerization step is influenced by the physical nature of the DNA lesion, that is, miscoding versus non-instructional. Collectively, these studies highlight the importance of nucleobase desolvation as a key physical feature that enhances the misreplication of structurally diverse DNA lesions.
\end{abstract}

\section{Introduction}

Maintaining fidelity during DNA replication is essential for the survival and propagation of nearly all forms of life. Much of the burden in maintaining genomic fidelity lies on the ability of replicative DNA polymerases to catalyze DNA synthesis with remarkable accuracy [1]. Most DNA polymerases involved in chromosomal replication make one mistake every $10^{6}-10^{7}$ opportunities [2]. This low error rate is very impressive considering that DNA polymerases maintain this remarkable accuracy while performing DNA synthesis with incredibly high catalytic efficiencies approaching diffusion limits of catalysis $\left(10^{8} \mathrm{M}^{-1} \mathrm{~s}^{-1}\right)$. For example, the highfidelity bacteriophage T4 DNA polymerase (gp43) incorporates the correct nucleotide, adenosine-2'deoxyriboside triphosphate (dATP), opposite its correct templating base partner $\mathrm{T}$ with an efficiency of $\sim 10^{7} \mathrm{M}^{-1} \mathrm{~s}^{-1}$ [3]. This is achieved through high binding affinity $\left(K_{d} \sim 10 \mu \mathrm{M}\right)$ for the correct nucleotide coupled with a fast rate constant $\left(k_{\text {pol }} \sim 100 \mathrm{~s}^{-1}\right)$ for incorporation [3]. Historically, both kinetic steps have been attributed to hydrogen-bonding interactions that guide the incorporation of the correct nucleotide oppose its templating partner [4-6]. As expected, inappropriate modifications to the templating base can adversely alter these hydrogen-bonding interactions to subsequently increase the ability for a replicative DNA polymerase to misinsert an incorrect nucleotide. As a consequence, the misreplication of damaged DNA can cause mutagenic events that initiate genetic diseases such as cancer [7-9].

DNA lesions can be classified into three distinct categories based on their physical nature. These categories include bulky lesions such as pyrimidine dimers, miscoding lesions such as 8-oxo-guanine (8-oxo-G), and non-instructional lesions such as 
abasic sites and double-strand DNA breaks (DSBs) [10-12]. There are several DNA repair pathways that can correct these lesions. [13] However, under certain conditions, these repair pathways can become overwhelmed, causing a large number of unrepaired lesions to persist. This can lead to an increased opportunity for their inappropriate replication in a process termed translesion DNA synthesis (TLS) [14-16]. Although TLS activity can be error-prone and reduce genomic fidelity, this activity is essential, as most cells would die if unrepaired DNA lesions were not efficiently replicated by specialized DNA polymerases such as pol eta, pol kappa, and pol iota.

One commonly formed DNA lesion that can produce devastating effects on cellular function is the abasic site $[17,18]$. Although this DNA lesion lacks hydrogen-bonding information, several DNA polymerases can efficiently by-pass this lesion under in vitro and in vivo conditions [19-22]. In most instances, dATP is preferentially incorporated opposite this non-instructional lesion, and this unusual phenomenon is termed the "A-rule" of TLS [23]. We previously used the bacteriophage T4 DNA polymerase, gp43, as a model high-fidelity DNA polymerase to understand the molecular forces associated with this preferential incorporation [24-29]. These studies quantified the ability of gp43 to incorporate modified purine analogs and 5-substituted indolyl nucleotides opposite an abasic site. Results from these studies demonstrated that alkylated purine analogs such as $N^{6}$-methyl-adenosine-2'-deoxyriboside triphosphate $\left(N^{6}\right.$-Me-dATP) and $O^{6}$-methylguanosine-guanosine$2^{\prime}$-deoxyriboside triphosphate ( $O^{6}$-Me-dGTP) were utilized more efficiently than dATP, and this was caused by increases in $k_{\text {pol }}$ coupled with decreases in the $K_{d}$ value for the modified nucleotide [25]. More impressive results were obtained using non-natural indolyl analogs such as 5-nitro-indolyl-2'-deoxyriboside triphosphate (5-NITP) [26]. In this case, analogs possessing increased $\pi$-electron surface area were utilized 1000-fold more efficiently than dATP [26-29]. Based upon these data, we developed the model depicted in Fig. 1a that highlights the importance of nucleobase desolvation toward enhancing the

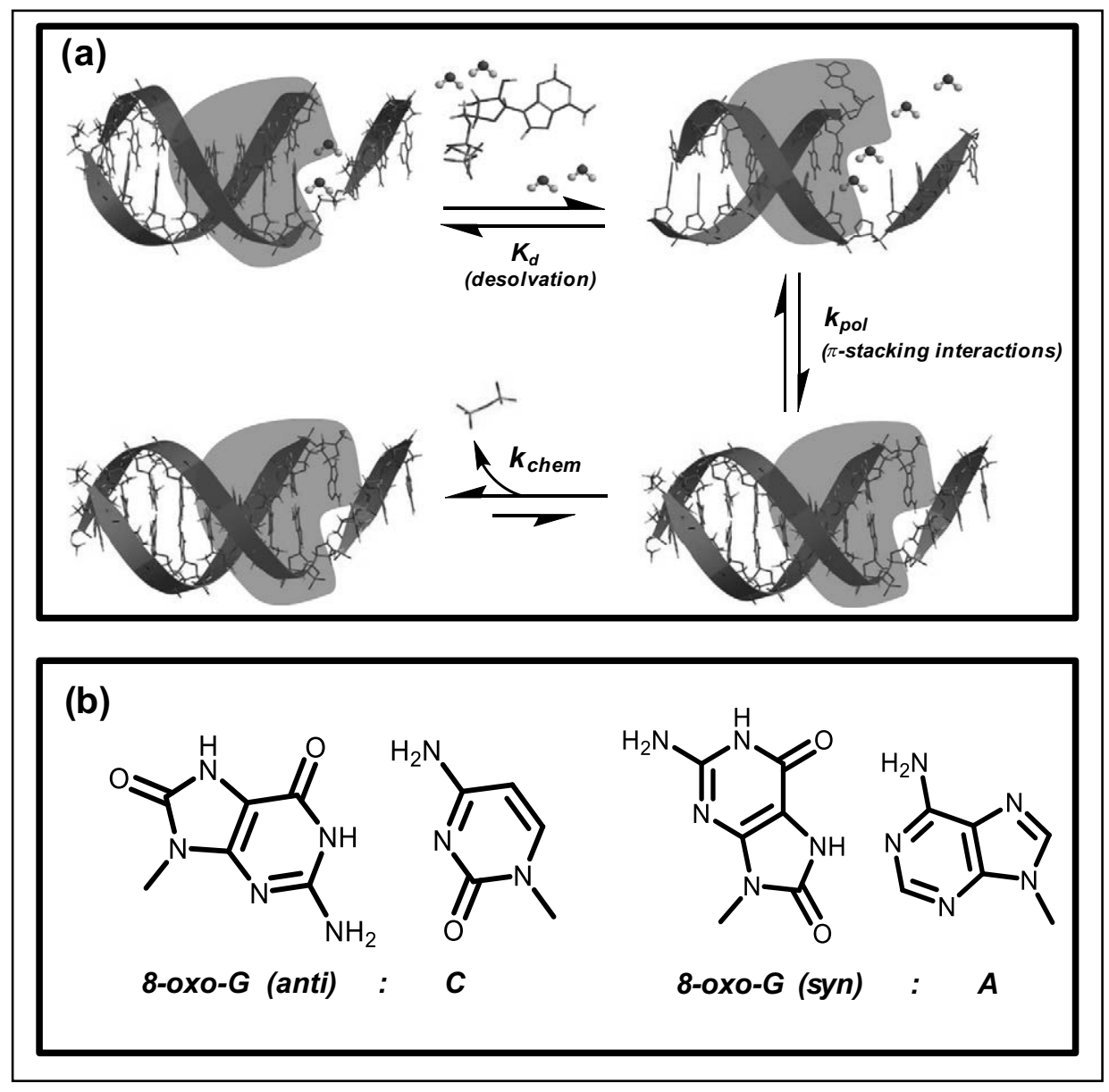

Fig. 1. (a) Model illustrating the role of different molecular forces used to facilitate the nucleotide binding step and the conformational change step preceding the chemistry step during the replication of an abasic site, a non-instructional lesion. (b) The replication of 8-oxo-G can be "error-free" (dCMP insertion) or "error-prone" (dAMP insertion). 
binding affinity of the incoming nucleotide, while increased $\pi$-electron density influences the rate of the conformational change step that precedes phosphoryl transfer [30].

In this report, we evaluate if this molecular mechanism is used universally by high-fidelity DNA polymerases during the replication of DNA lesions that are structurally distinct from abasic sites. This was approached by quantifying the kinetic parameters for the incorporation of modified and non-natural analogs opposite 8-oxo-G catalyzed by gp43exo-. We chose 8-oxo-G since the oxidized DNA lesion possesses dual coding properties as it can base pair with dCTP when in the anti conformation or with dATP when in the syn conformation (Fig. 1b). However, like an abasic site, several replicative DNA polymerases such as gp43 and human DNA polymerases including pol $\delta$ and pol $Y$ efficiently misincorporate dATP opposite 8-oxo-G [31-35]. In the case of pol $\gamma$, for example, adenosine-2'-deoxyriboside monophosphate (dAMP) is stably inserted and frequently elongated despite the presence of rigorous exonuclease proofreading activity with the mitochondrial DNA polymerase [35]. At face value, the preferential misinsertion of dATP opposite both types of lesions suggests that a common mechanism is used to replicate damaged DNA. Indeed, the results generated here with 8-oxo-G demonstrate that the binding affinity of the incoming deoxynucleoside triphosphate (dNTP) for gp43exo- is controlled by the overall hydrophobicity of the nucleobase. However, the rate constant for polymerization is regulated by different biophysical features that are dependent upon whether the DNA lesion is miscoding or non-instructional. Specifically, during the replication of non-instructional lesions, the rate constant for the polymerization step is controlled by m-electron density present on the incoming nucleotide, whereas the data presented here show that hydrogen-bonding interactions play a much larger role with miscoding lesions such as 8-oxo-G. Collectively, these studies provide additional insight into how different molecular forces are used by high-fidelity DNA polymerases during the misreplication of structurally distinct DNA lesions.

\section{Results}

\section{Incorporation of natural nucleotides opposite guanine (G) and 8-0xo-G}

Initial experiments compared the efficiency for incorporating dCTP and dATP opposite G or 8-oxo-G by gp43exo- . Figure 2a provides the sequences of the DNA substrates used in this study containing either $G$ or 8-oxo-G at the 14th position of the template strand.
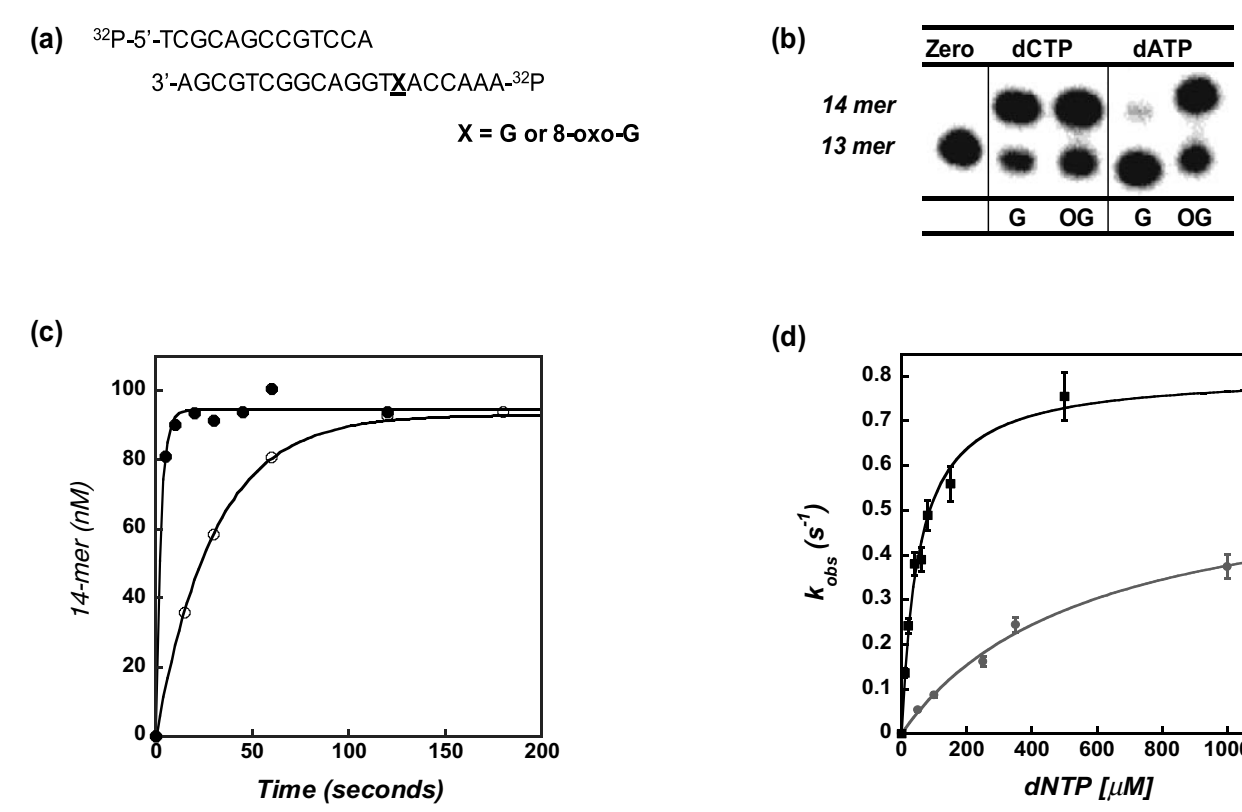

(d)

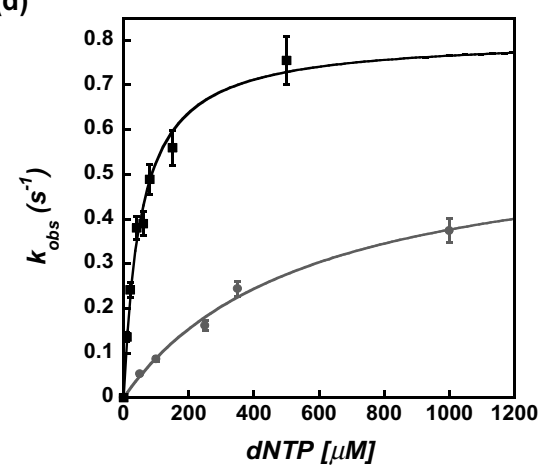

Fig. 2. (a) DNA substrate used in these studies. $X$ in the template at position 14 denotes $G$ or 8 -oxo-G. (b) Denaturing gel electrophoresis images comparing the incorporation of dCTP and dATP opposite undamaged G (13/20 $\mathrm{G}$ ) and 8-oxo-G $\left(13 / 20_{8-o x o-G}\right)$ by gp43exo ${ }^{-}$. Assays were performed using a fixed concentration of $100 \mu \mathrm{M}$ nucleotide substrate. Reactions were quenched at a time interval of $120 \mathrm{~s}$. (c) Time course plots comparing the enzymatic incorporation of dCTP $(\bullet)$ and

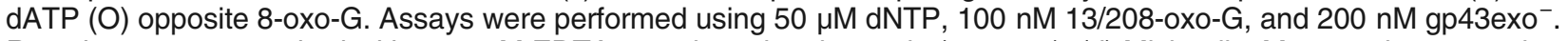
Reactions were quenched with $200 \mathrm{mM}$ EDTA at various time intervals (0-300 s). (d) Michaelis-Menten plot comparing the insertion of dCTP $(\bullet)$ versus $\mathrm{dATP}(\bullet)$ opposite 8 -oxo-G by gp43exo ${ }^{-}$. 
Representative gel electrophoresis images provided in Fig. $2 b$ show that gp43exo- efficiently incorporates dCTP opposite $G$ while poorly incorporating dATP opposite an unmodified G. Gp43exo ${ }^{-}$also inserts dCTP opposite 8-oxo-G, albeit with a lower overall efficiency. Surprisingly, this high-fidelity polymerase misinserts dATP opposite the oxidized lesion with an efficiency that is comparable to dCTP.

To further quantify the replication of 8-oxo-G, we measured the kinetic parameters $k_{\mathrm{pol}}, K_{\mathrm{d}}$, and $k_{\mathrm{pol}} / K_{\mathrm{d}}$ for the insertion of dCTP and dATP opposite 8-oxo-G using single turnover conditions, that is, the concentration of DNA polymerase is in molar excess versus DNA substrate. Figure 2c provides time courses comparing the incorporation of $50 \mu \mathrm{M}$ dCTP versus $50 \mu \mathrm{M}$ dATP opposite 8-oxo-G and demonstrates that dCTP is utilized more efficiently than dATP. Representative Michaelis-Menten plots provided in Fig. $2 \mathrm{c}$ were used to define these kinetic parameters for inserting dCTP (black) and dATP (red) opposite 8-oxo-G. These values, summarized in Table 1, are used to compare correct versus translesion DNA synthesis catalyzed by gp43exo- ${ }^{-}$. During normal DNA synthesis, gp43exo- efficiently incorporates dCTP opposite $\mathrm{G}$ with a low $K_{\mathrm{d}}$ value of $6 \mu \mathrm{M}$ and fast $k_{\mathrm{pol}}$ value of $118 \mathrm{~s}^{-1}$ [36]. When replicating 8-oxo-G, however, the catalytic efficiency for inserting dCTP is $\sim 1200$ fold lower (compare 1.97 ${ }^{*} 10^{7} \mathrm{M}^{-1} \mathrm{~s}^{-1}$ versus $1.60 * 10^{4} \mathrm{M}^{-1} \mathrm{~s}^{-1}$, respectively). This reduction reflects a $\sim 8$-fold increase in $K_{\mathrm{d}}$ value $(49 \mu \mathrm{M})$ combined with a 170 -fold reduction in $k_{\text {pol }}\left(0.707 \mathrm{~s}^{-1}\right)$. Surprisingly, the efficiency for inserting dATP opposite 8-oxo-G is only $\sim 17$-fold lower than dCTP (compare $1.0 * 10^{3} \mathrm{M}^{-1} \mathrm{~s}^{-1}$ versus $1.6 * 10^{4} \mathrm{M}^{-1} \mathrm{~s}^{-1}$, respectively). The reduced efficiency for utilizing dATP is not caused by an effect on the polymerization rate constant, as the $k_{\text {pol }}$ value for dATP is nearly identical to that measured for dCTP (compare $0.535 \mathrm{~s}^{-1}$ versus $0.707 \mathrm{~s}^{-1}$, respectively). Instead, the reduced efficiency is caused almost exclusively by $\mathrm{a} \sim 10$-fold decrease in binding affinity (compare $K_{\mathrm{d}}$ values of $566 \mu \mathrm{M}$ versus $49 \mu \mathrm{M}$, respectively). As expected, the high-fidelity DNA polymerase does not incorporate dATP opposite

Table 1. Summary of kinetic parameters comparing the incorporation of natural nucleotides opposite $\mathrm{G}$ and 8-oxo-G by gp43exo-

\begin{tabular}{lllll}
\hline DNA substrate & dNTP & $K_{\mathrm{d}}(\mu \mathrm{M})$ & \multicolumn{1}{c}{$k_{\text {pol }}\left(\mathrm{s}^{-1}\right)$} & $\begin{array}{c}k_{\text {pol }} / K_{\mathrm{d}} \\
\left(\mathrm{M}^{-1} \mathrm{~s}^{-1}\right)\end{array}$ \\
\hline $13 / 20_{\mathrm{G}}$ & dCTP & $6 \pm 1$ & $118 \pm 7$ & $1.97^{*} 10^{7}$ \\
$13 / 20_{8-\mathrm{oxo}-\mathrm{G}}$ & dATP & ND & ND & ND \\
& dATP & $49 \pm 8$ & $0.707 \pm 0.055$ & $1.6^{*} 10^{4}$ \\
& dATP & $566 \pm 24$ & $0.535 \pm 0.015$ & $1.0^{*} 10^{3}$ \\
\hline
\end{tabular}

ND indicates that defined values corresponding to $K_{\mathrm{d}}, K_{\mathrm{pol}}$, and $k_{\text {pol }} / K_{d}$ could not be accurately determined since the amount of product formed at the highest concentration tested $(500 \mu \mathrm{M})$ was $<10 \%$ even at the longest time point examined $(\Delta t=20 \mathrm{~min})$. an unmodified $\mathrm{G}$. Thus, the ability of $\mathrm{gp} 43 \mathrm{exo}^{-}$to misincorporate dATP opposite 8-oxo-G highlights the pro-mutagenic properties of the oxidized lesion.

\section{Incorporation of modified nucleotide analogs opposite $\mathrm{G}$ and 8-oxo-G}

To further investigate the molecular forces associated with the pro-mutagenic replication of 8-oxo-G, we measured the kinetic parameters for modified purine analogs containing alterations in hydrogen-bonding groups. These modified nucleotides, illustrated in Fig. 3a, are classified into three distinct groups. The first includes alkylated nucleotides such as $N^{6}$-MedGTP, $O^{6}$-Me-dGTP, and $N^{2}$-methyl-guanosine-2'deoxyriboside triphosphate $\left(N^{2}\right.$-Me-dGTP) that examine the contributions of hydrogen-bonding interactions, shape complementarity/steric fit, and nucleobase hydrophobicity. The second group includes the analogs 6-chloropurine-2'-deoxyadenosine- $5^{\prime}$ triphosphate (6-Cl-dATP) and 6-chloro-2-amino-2'deoxyriboside-5'-triphosphate (6-Cl-2APTP), which replace a hydrogen-bonding group with a halogen. These halogenated analogs were used to evaluate the contributions of shape complementarity/steric fit and nucleobase hydrophobicity. The third group are purines in which hydrogen-bonding groups are removed [2'-deoxyinosine- $5^{\prime}$-triphosphate (dITP)] or added (2,6-dATP) and were used to interrogate the importance of hydrogen-bonding interactions.

Experiments were performed, preincubating $200 \mathrm{nM}$ gp43exo ${ }^{-}$with $100 \mathrm{nM} 13 / 20_{\mathrm{G}}$ or $13 / 20_{\text {8-oxo-G }}$ and initiating the reaction through the addition of $100 \mu \mathrm{M}$ dNTP. The gel electrophoresis image provided in Fig. $3 b$ shows that most of these modified analogs are effectively incorporated opposite 8-oxo-G and poorly inserted opposite an unmodified $\mathrm{G}$. It is quite interesting that gp43 exo- misinserts dGMP more efficiently opposite $\mathrm{G}$ compared to 8-oxo-G. While the molecular reason for this effect is currently unknown, this dichotomy in nucleotide utilization represents a potentially important feature of substrate discrimination catalyzed by high-fidelity DNA polymerases. Regardless, it is clear that the majority of these modified analogs show a higher selectivity for insertion opposite 8-oxo-G despite the fact that they are incorporated less efficiently than dATP opposite the miscoding DNA lesion. At face value, this result suggests that hydrogen-bonding interactions are indeed important factors for effectively replicating the miscoding DNA lesion.

To verify this conclusion, we measured the kinetic parameters $k_{\text {pol }} / K_{\mathrm{d}}, K_{\mathrm{pol}}$, and $K_{\mathrm{d}}$ to better define the influence of hydrogen-bonding interactions and nucleobase hydrophobicity and steric fit/shape complementarity on nucleotide misinsertion. MichaelisMenten plots provided in Fig. $3 \mathrm{c}$ compare the utilization of dATP versus $N^{6}$-Me-dATP and 6-Cl-dATP for insertion opposite 8-oxo-G. These data show that both 


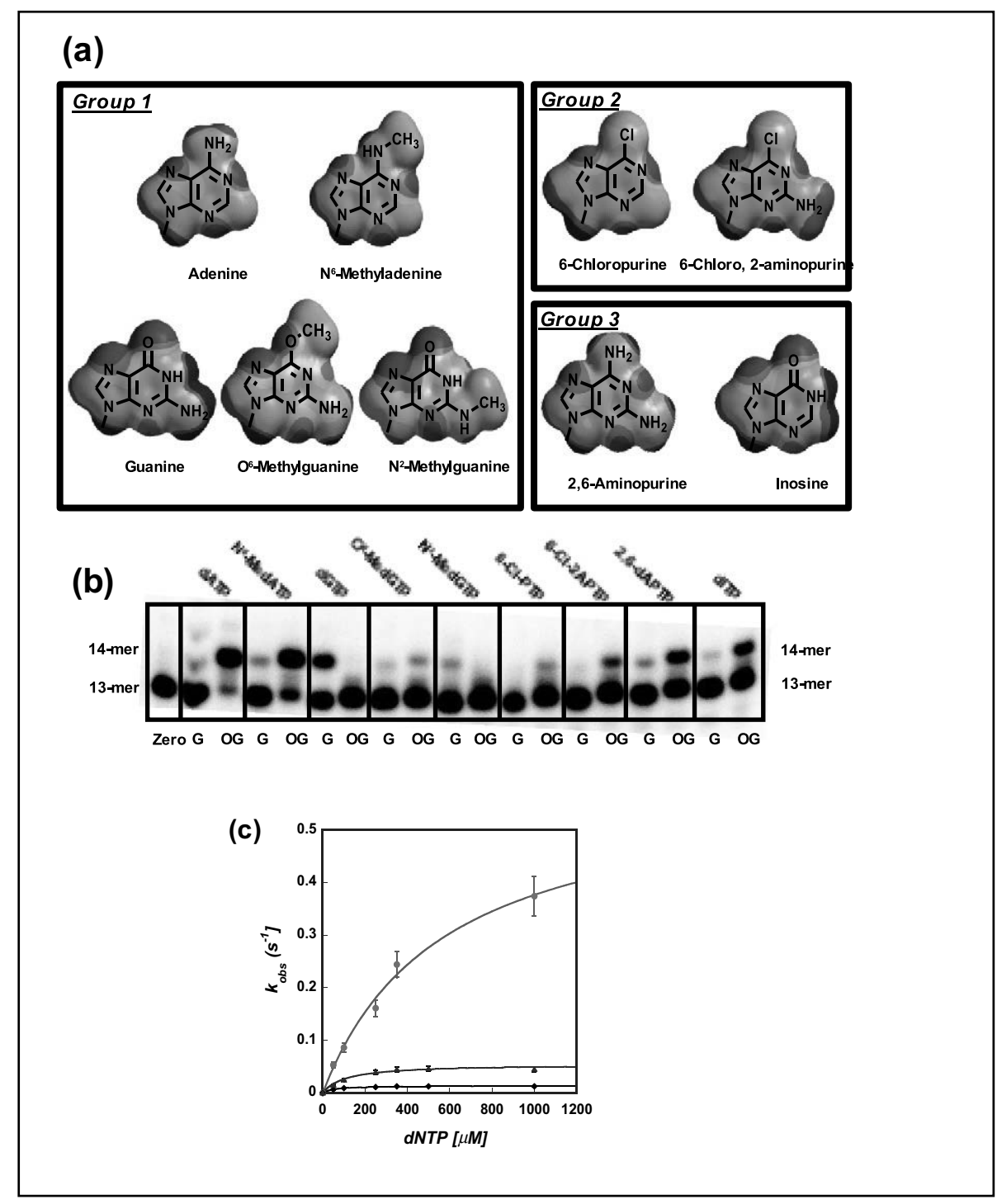

Fig. 3. (a) Chemical structures and electrostatic potential maps of the modified purine nucleotide analogs used in this study. For convenience, only the nucleobases are shown. The charges in the electrostatic maps are represented by red $=$ negative green $=$ neutral, and blue $=$ positive. (b) Denaturing gel electrophoresis images comparing the incorporation of modified nucleotide analogs opposite $G\left(13 / 20_{G}\right)$ and $8-0 x o-G\left(13 / 20_{8-o x o-G}\right)$ by gp43exo ${ }^{-}$. Assays were performed using a fixed concentration of $100 \mu \mathrm{M}$ nucleotide substrate. Reactions were quenched at a time interval of 120 s. (c) Michaelis-Menten plots comparing the utilization of $\operatorname{dATP}(\bullet), N^{6}-\mathrm{Me}-\mathrm{dATP}(\boldsymbol{\Delta})$, and $6-\mathrm{Cl}-\mathrm{PTP}(\bullet)$ during the replication of $8-0 \times 0-G\left(13 / 20_{8-o x o-G}\right)$.

modified analogs are utilized far less efficiently than dATP. Close inspection of the kinetic parameters summarized in Table 2 reveals important mechanistic insight into this phenomenon. For instance, the reduced $k_{\text {pol }} / K_{\mathrm{d}}$ values for both modified nucleotides are caused almost exclusively by large reductions in their $k_{\text {pol }}$ values that are partially offset by increases in binding affinity for the nucleotide. Specifically, the $K_{d}$ values for $N^{6}$-Me-dATP and 6-Cl-PTP are 4- and 11-fold lower than dATP. Inspection of the kinetic parameters with the biophysical parameters (surface area, volume, and solvation energies) provided in Table 2 shows that the enhanced binding affinity of these modified nucleotides correlates better with decreases in their associated solvation energies compared to differences in size or shape. In addition, these data also show that alterations in the hydrogen-bonding interactions produce a negative effect on the polymerization rate constant and again are independent of size and shape of the incoming nucleotide. 
Table 2. Summary of kinetic parameters for the incorporation of modified nucleotide analogs opposite 8-oxo-G by gp43exo-

\begin{tabular}{llllccc}
\hline dNTP & \multicolumn{1}{c}{$K_{\mathrm{d}}(\mu \mathrm{M})$} & \multicolumn{1}{c}{$k_{\text {pol }}\left(\mathrm{sec}^{-1}\right)$} & $\begin{array}{c}k_{\mathrm{pol}} / K_{\mathrm{d}} \\
\left(\mathrm{M}^{-1} \mathrm{~s}^{-1}\right)\end{array}$ & Surface area $\left(\AA^{2}\right)$ & $\begin{array}{c}\text { Volume } \\
\left(\AA^{3}\right)\end{array}$ & Solvation energy $(\mathrm{kJ} / \mathrm{mol})$ \\
\hline dATP & $566 \pm 24$ & $0.535 \pm 0.015$ & $1.0^{*} 10^{3}$ & 142.98 & 121.65 & -81.04 \\
$N^{6}$-Me-dATP & $135 \pm 41$ & $0.056 \pm 0.005$ & $4.1^{*} 10^{2}$ & 164.95 & 142.08 & -67.61 \\
6-Cl-PTP & $51 \pm 17$ & $0.012 \pm 0.001$ & $2.3^{*} 10^{2}$ & 145.22 & 125.13 & -66.31 \\
6-Cl-2dATP & $145 \pm 33$ & $0.049 \pm 0.003$ & $3.3^{*} 10^{2}$ & 158.7 & 135.13 & -78.93 \\
dGTP & $\mathrm{ND}$ & $\mathrm{ND}$ & $\mathrm{ND}$ & 152.50 & 129.03 & -100.51 \\
$O^{6}$-Me-dGTP & $82 \pm 11$ & $0.023 \pm 0.001$ & $2.7 * 10^{2}$ & 174.49 & 149.14 & -79.41 \\
$N^{2}$-Me-dGTP & $\mathrm{ND}$ & $\mathrm{ND}$ & $\mathrm{ND}$ & 174.34 & 149.41 & -85.91 \\
2,6-APTP & $1370 \pm 410$ & $0.787 \pm 0.156$ & $0.5 * 10^{3}$ & 156.44 & 131.65 & -95.35 \\
dITP & $28 \pm 8$ & $0.008 \pm 0.005$ & $2.9 * 10^{2}$ & 138.96 & 119.00 & -89.08 \\
\hline
\end{tabular}

ND indicates that defined values corresponding to $K_{\mathrm{d}}, K_{\mathrm{pol}}$, and $k_{\mathrm{pol}} / K_{\mathrm{d}}$ could not be accurately determined since the amount of product formed at the highest concentration tested $(500 \mu \mathrm{M})$ was $<10 \%$ even at the longest time point examined $(\Delta t=20 \mathrm{~min})$.

Similar results are obtained with the majority of nucleotide analogs tested here, as modifications to one or more hydrogen-bonding groups cause a 10 -fold reduction in their overall catalytic efficiency for insertion (Table 2). Two relevant examples are 6-Cl-2dATP and $O^{6}$-Me-dGTP, as their lower catalytic efficiencies are caused by significant reductions in their $k_{\text {pol }}$ values that are offset by increases in binding affinities for the incoming nucleotide. As before, these data are consistent with a mechanism in which ground state binding of the incoming nucleotide is influenced by the lower solvation energies of the incoming nucleotide, while the $k_{\text {pol }}$ value is controlled by hydrogen-bonding interactions with the oxidized lesion. Further support of this mechanism is provided by the kinetic parameters for 2,6-dATP in which the introduction of a hydrogen-bonding group produces a 2.4-fold increase in $K_{d}$ coupled with a slight increase in $k_{\text {pol }}$ compared to dATP (compare $0.787 \mathrm{~s}^{-1}$ versus $0.535 \mathrm{~s}^{-1}$, respectively).

We note, however, that there are two unique exceptions to this mechanism. The first is dITP, which, despite having a natural hydrogen-bonding group, displays high binding affinity and a low $k_{\text {pol }}$ value. The low $k_{\text {pol }}$ value for dITP likely reflects a lack of complementarity in hydrogen-bonding interactions between the nucleotide and the oxidized lesion. However, perhaps the most surprising result is that obtained for $N^{2}$-Me-dGTP, as this hydrophobic analog is not utilized by gp43 exo $^{-}$during the replication of $8-0 x 0-G$. This negative result is particularly interesting since we previously demonstrated that the specialized DNA polymerase, pol $\eta$, utilizes $N^{2}$-Me-dGTP 10-fold more efficiently than dATP when replicating the oxidized DNA lesion [37]. In the case of pol $\eta$, the increased efficiency reflects a very low $K_{\mathrm{m}}$ for $N^{2}$-Me-dGTP $(0.12 \mu \mathrm{M})$ rather than an effect on $k_{\text {cat }}$. Regardless, the dichotomy in utilizing $N^{2}$-Me-dGTP prompted us to investigate if $N^{2}$-Me-dGTP acts as an inhibitor against the high-fidelity bacteriophage T4 DNA polymerase.

\section{Inhibition studies using $N^{2}$-Me-dGTP}

To examine the potential inhibitory effects of $N^{2}$ Me-dGTP against gp43exo ${ }^{-}$, we performed single turnover experiments measuring the rate constant for dATP incorporation opposite 8-oxo-G in the absence and presence of increasing concentrations of $N^{2}$-Me-dGTP. The data provided in Fig. 4a show that the rate constant for incorporating dATP decreases as the concentration of $N^{2}$-Me-dGTP is increased. The plot of rate constants $\left(k_{\text {obs }}\right)$ versus $N^{2}$-MedGTP concentration was used to define an apparent $K_{\mathrm{i}}$ value of $240 \pm 35 \mu \mathrm{M}$ (Fig. 4b). Correcting for the concentration of the substrate, dATP, yielded a true $K_{\mathrm{i}}$ value of $220 \pm 30 \mu \mathrm{M}$ for $N^{2}$-Me-dGTP. Collectively, these data indicate that the modified analog binds to the Pol:DNA complex, albeit with rather weak affinity.

We next performed a series of modified pulse-chase experiments as outlined in Fig. $4 \mathrm{c}$ to evaluate if $N^{2}$-MedGTP binding induces the conformational change step that precedes phosphoryl transfer. In these assays, DNA substrate and gp43exo- were incubated with $220 \mu \mathrm{M}$ of $N^{2}$-Me-dGTP ( $K_{\mathrm{i}}$ concentration) for variable periods of time $(\Delta t=0$ to $30 \mathrm{~min})$ and then chased with $50 \mu \mathrm{M}$ dATP. During this incubation period, the formed Pol:DNA: $N^{2}$-Me-dGTP complex is given sufficient time to potentially undergo a conformational change to form the Pol*:DNA: $N^{2}-\mathrm{Me}-$ dGTP complex. In this scenario, any $N^{2}$-Me-dGTP bound to the gp43:DNA complex will sequester the DNA polymerase into a dead-end complex and prevent the binding of dATP. The formation of this dead-end complex should generate a concomitant reduction in the amount of product formed by the incorporation of dATP opposite 8-oxo-G. However, the data provided in Fig. 4d show a minimal effect on the amplitude in product formation as a function of "chase" time with dATP. The minimal effect on dATP incorporation indicates that the binding of $N^{2}$-MedGTP is in rapid equilibrium with the polymerase:DNA complex and suggests that this modified nucleotide is 


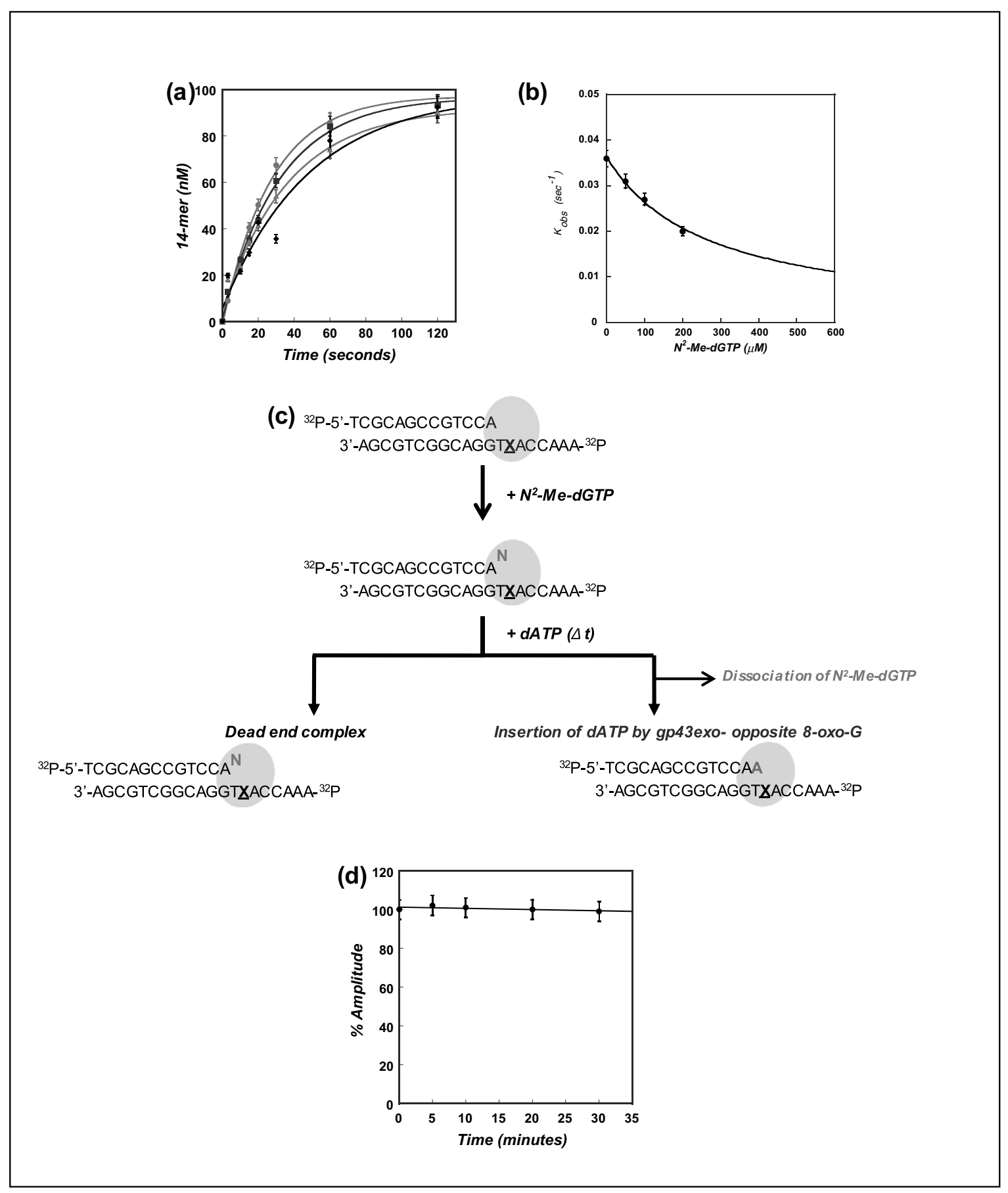

Fig. 4. (a) $N^{2}$-Me-dGTP acts as a competitive inhibitor for the incorporation of dATP opposite 8-oxo-G. gp43exo$(200 \mathrm{nM})$ and 5'-labeled 13/20 ${ }_{8-o x o-G}-\operatorname{mer}(100 \mathrm{nM})$ were preincubated with $10 \mathrm{mM} \mathrm{Mg}(\mathrm{OAc})_{2}$. Reactions were initiated with a mixture of $50 \mu \mathrm{M} \mathrm{dATP}(\bullet)$ and $N^{2}$-Me-dGTP in variable concentrations of $50 \mu \mathrm{M}(\bullet), 100 \mu \mathrm{M}(\bullet)$, and $200 \mu \mathrm{M}(\bullet)$. Reactions were quenched with $500 \mathrm{mM}$ EDTA at variable time points. Nucleotide incorporation was analyzed by denaturing gel electrophoresis. (b) Dixon plot analysis used to measure the apparent $K_{\mathrm{i}}$ value for $N^{2}$-Me-dGTP. Correcting for the concentration of substrate, dATP, used in these experiments by applying the Cheng-Prusoff relationship yields a true $K_{\mathrm{i}}$ value of $220 \mu \mathrm{M}$. (c) Experimental protocol used in pulse chase experiments to monitor the conformational change step preceding phosphoryl transfer. Gp43exo ${ }^{-}$and $13 / 20_{8-o x o-G}$ were incubated with a $K_{\mathrm{i}}$ concentration of $N^{2}$-Me-dGTP for variable periods of time ( $\Delta t=0$ to $30 \mathrm{~min}$ ) and then chased with $50 \mu \mathrm{M} \mathrm{dATP}$. (d) Plot of percentage amplitude in dATP

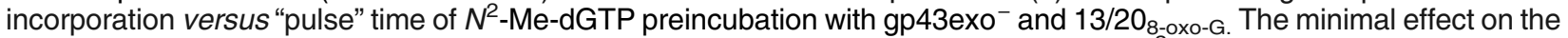
burst amplitude in product formation as a function of incubation time suggests that $N^{2}$-Me-dGTP does not induce a conformational change in the gp43exo-. 
unable to induce the conformational change that is required for subsequent incorporation of $N^{2}$-Me-dGTP opposite 8-oxo-G. An alternative possibility is that the rate constant to reverse the conformational change is sufficiently fast such that any bound $N^{2}$-Me-dGTP is rapidly released.

\section{Incorporating non-natural nucleotide analogs opposite G and 8-oxo-G}

To further interrogate the roles of nucleobase hydrophobicity and hydrogen-bonding interactions, we quantified the incorporation of several 5 '-substituted

(a)
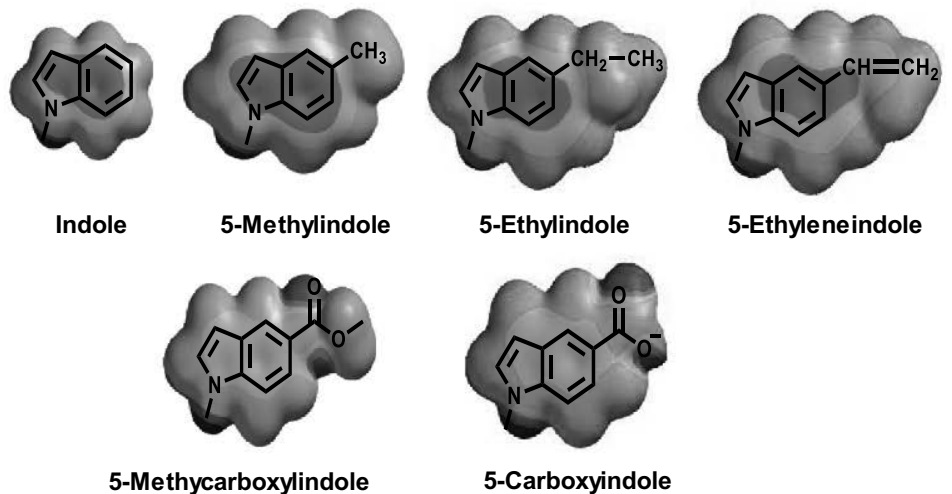

5-Ethyleneindole

5-Methycarboxylindole

5-Carboxyindole

(b)

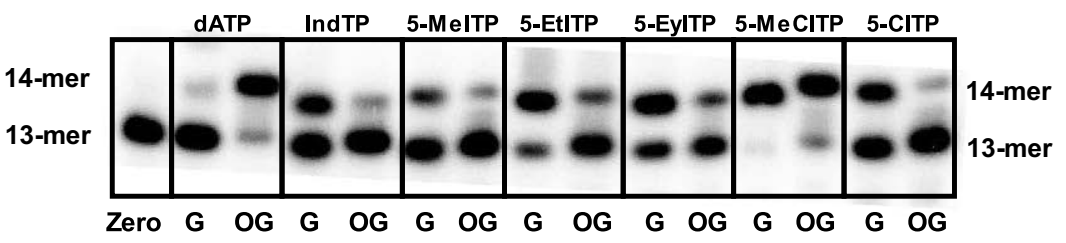

(c)

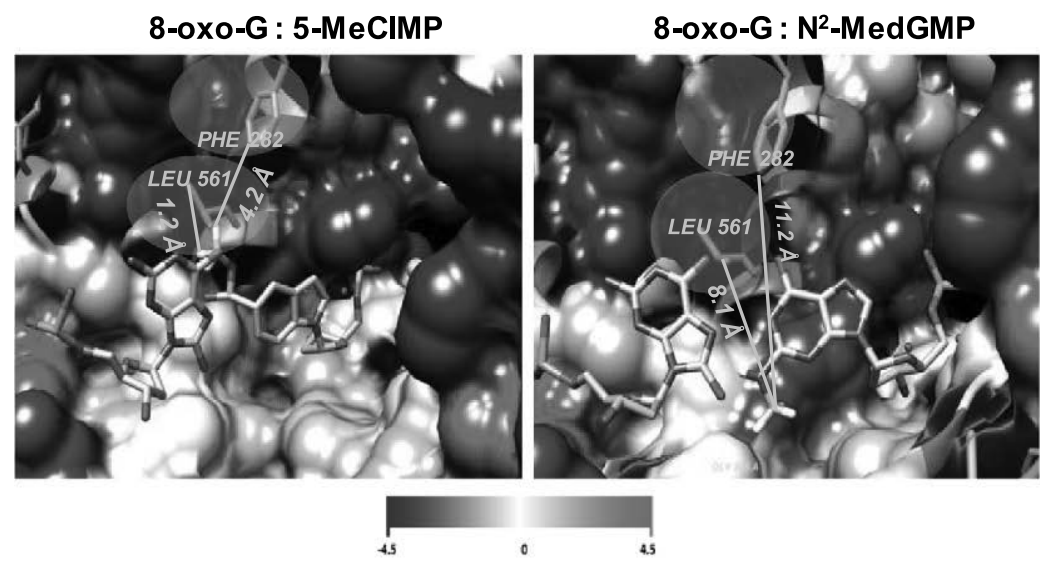

Fig. 5. (a) Chemical structures and electrostatic potential maps of non-natural nucleotide analogs used in this study. For convenience, only the nucleobases are shown here. The charges in the electrostatic maps are represented by red $=$ negative, green = neutral, and blue = positive. (b) Denaturing gel electrophoresis images comparing the incorporation of non-natural nucleotide analogs opposite $\mathrm{G}\left(13 / 20_{\mathrm{G}}\right)$ versus 8-oxo-G (13/208-oxo-G) by gp43exo ${ }^{-}$. Kinetic assays were performed as described in the text. (c) Molecular models for 8-oxo-G paired opposite 5-MeCIMP (left panel) and $N^{2}$-MedGMP (right panel) in the active site of RB69 DNA polymerase. The models were generated using molecular modeling programs Molecular Operating Environment and Chimera. The amino acid residues in the active site are color-coded based on Kyle Doolittle hydrophobicity scale, where blue denotes hydrophilic amino acid residues and red denotes hydrophobic amino acid residues. The close proximity of L561 and F282 (1.2 $\AA$ and $4.2 \AA$ ) may play important roles for the efficient insertion of 5-MeCIMP opposite 8-oxo-G. This is further supported by the inability of gp43exo ${ }^{-}$to insert $N^{2}$-Me-dGMP, as the hydrophobic $-\mathrm{CH}_{3}$ at the N2 position of G is $8.1 \AA$ away from L561 and $11.2 \AA$ from F282. 
indolyl-2'-deoxynucleotide analogs depicted in Fig. 5a opposite 8-oxo-G and G. Gel electrophoresis data provided in Fig. $5 \mathrm{~b}$ show that these analogs act as modest-to-poor substrates for gp43exo ${ }^{-}$when replicating 8-oxo-G. In fact, the majority of the non-natural nucleotide analogs show preferential incorporation opposite $G$ rather than the oxidized DNA lesion. Regardless, the kinetic data provided in Table 3 show that the catalytic efficiencies for these modified analogs are roughly 2- to 10-fold lower than dATP. The lone exception is 5-methylcarboxyl-indolyl-2'deoxyriboside triphosphate (5-MeCITP), which shows a fourfold higher efficiency for insertion opposite 8-oxo-G. Despite this exception, the lower catalytic efficiencies reflect significant reductions in their $k_{\text {pol }}$ values and again suggest that the polymerization rate constant is highly sensitive to the formation of proper hydrogen-bonding interactions. However, it is clear that nucleobase hydrophobicity also influences the binding affinity for the incoming nucleotide. For example, hydrophobic analogs such as 5-methy-lindolyl-2'deoxyriboside triphosphate (5-MelTP) and 5-ethylindolyl-2'-deoxyriboside triphosphate (5-EtITP) have lower $K_{d}$ values of $260 \mu \mathrm{M}$ and $184 \mu \mathrm{M}$, respectively, compared to dATP. Surprisingly, 5-ethyleneindolyl-2'-deoxyriboside triphosphate (5-EyITP), which is roughly the same size as 5-EtITP, binds with a significantly higher affinity $\left(K_{d}=41 \mu \mathrm{M}\right)$ than 5-EtITP $\left(K_{d}=184 \mu \mathrm{M}\right)$. In this case, the enhanced binding affinity for 5-EyITP is likely attributed to a combination of hydrophobicity and increased $\pi$-electron density present at the ethynyl moiety. Consistent with the argument is the observation that 5-MeCITP, a hydrophobic analog, which also possesses significant $\pi$-electron density, displays a relatively low $K_{d}$ value of $57 \mu \mathrm{M}$. Furthermore, the hydrophilic analog, 5-carboxylindolyl-2'-deoxyriboside triphosphate (5-CITP), is poorly incorporated opposite 8-oxo-G, and this is likely caused by poor binding affinity induced by the presence of the carboxyl moiety.

Entropic stabilization is best defined as a decrease in the randomness of a chemical system. Indeed, the removal or reorganization of water from a substrate represents a decrease in randomness. However, we propose that hydrophobic residues within the active site of the polymerase function to repel water, and this causes an overall net attraction for the non-polar nucleobases in the hydrophobic interior of the DNA helix. This is consistent with studies performed demonstrating that hydrophobic interactions, as quantified by the amount of hydrophobic surface buried upon ligand binding, are a good parameter that correlates well with increased binding energy for a substrate or ligand $[38,39]$.

Further support for the involvement of hydrophobicity toward improving nucleotide binding is provided by structural models of the active site of gp 43 provided in Fig. 5c. These models show the presence of two hydrophobic amino acids, L561 and F282, that lie in very close proximity (1.2 $\mathrm{A}$ and $4.2 \AA$, respectively) to the $-\mathrm{CH}_{3}$ group of 5-MeCITP. The potentially favorable Van der Waals interactions made between the hydrophobic methyl group and these hydrophobic amino acids could enhance the binding affinity of the incoming nucleotide via stabilization through weak enthalpic forces. The importance of this interaction is supported by the inability of gp43 to incorporate $N^{2}$-Me-dGTP. In this case, the longer distances of 8.1 $\AA$ and $11.2 \AA$ between L561 and F282, respectively, with the $-\mathrm{CH}_{3}$ moiety of $N^{2}$-Me-dGTP precludes favorable Van der Waals interactions, which may not facilitate a potential conformational change step. It should be noted that Fig. $5 \mathrm{c}$ shows the templating base in the syn conformation and the incoming nucleotide in the anti conformation. However, there is a formal possibility that the lesion adopts an anti conformation and the nucleotide adopts a syn conformation. This may be relevant with analogs that have larger modifications in positions that are along the Watson-Crick pairing edge of the base.

\section{Primer extension of 8-oxo-G is also influenced by hydrogen-bonding interactions}

We also examined the ability of gp43exo ${ }^{-}$to extend beyond various nucleotides paired opposite

Table 3. Summary of kinetic parameters for the incorporation of non-natural nucleotide analogs opposite 8-oxo-G by gp43exo-

\begin{tabular}{|c|c|c|c|c|c|c|}
\hline dNTP & $\begin{array}{c}K_{d} \\
(\mu \mathrm{M})\end{array}$ & $\begin{array}{c}k_{\mathrm{pol}} \\
\left(\mathrm{sec}^{-1}\right)\end{array}$ & $\begin{array}{c}k_{\mathrm{pol}} / K_{\mathrm{d}} \\
\left(\mathrm{M}^{-1} \mathrm{~s}^{-1}\right)\end{array}$ & $\begin{array}{c}\text { Surface area } \\
\left(\AA^{2}\right)\end{array}$ & $\begin{array}{l}\text { Volume } \\
\left(\AA^{3}\right)\end{array}$ & $\begin{array}{c}\text { Solvation energy } \\
(\mathrm{kJ} / \mathrm{mol})\end{array}$ \\
\hline dATP & $566 \pm 24$ & $0.535 \pm 0.015$ & $1.0 * 10^{3}$ & 142.98 & 121.65 & -81.04 \\
\hline indolyl-2'-deoxyriboside triphosphate & ND & ND & ND & 146.17 & 131.05 & -21.88 \\
\hline 5-MelTP & $260 \pm 98$ & $0.042 \pm 0.008$ & $1.62 * 10^{2}$ & 166.08 & 149.34 & -21.35 \\
\hline 5-EtITP & $184 \pm 36$ & $0.079 \pm 0.007$ & $4.3^{*} 10^{2}$ & 186.00 & 167.68 & -19.72 \\
\hline 5-EyITP & $41 \pm 9$ & $0.030 \pm 0.002$ & $7.14 * 10^{2}$ & 180.03 & 163.28 & -18.75 \\
\hline 5-MeCITP & $57 \pm 12$ & $0.231 \pm 0.021$ & $4.05 * 10^{3}$ & 198.82 & 179.02 & -27.95 \\
\hline 5-CITP & ND & ND & ND & 173.49 & 156.74 & -299.79 \\
\hline
\end{tabular}

ND indicates that defined values corresponding to $K_{\mathrm{d}}, K_{\mathrm{pol}}$, and $K_{\mathrm{pol}} / K_{\mathrm{d}}$ could not be accurately determined since the amount of product formed at the highest concentration tested $(500 \mu \mathrm{M})$ was $<10 \%$ even at the longest time point examined $(\Delta t=20 \mathrm{~min})$. 
8-oxo-G. In these experiments, we measured extension capabilities using nucleotide analogs including $N^{6}$-Me-dATP, $0^{6}$-Me-dGTP, 6-Cl-PTP, 5-EyITP, and 5-MeCITP, which are efficiently inserted opposite the DNA lesion and thus provide adequate signal-to-noise ratios needed to quantify elongation beyond the lesion. Assays were performed using single turnover conditions in which $200 \mathrm{nM}$ gp43exo

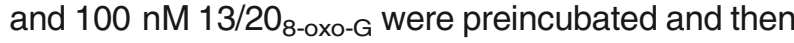
mixed with a fixed concentration of nucleotide $\left(100 \mu \mathrm{M}\right.$ dNTP) and $10 \mathrm{mM} \mathrm{Mg}^{2+}$ to initiate insertion opposite the lesion. After four half-lives, an aliquot of dTTP and dGTP ( $200 \mu \mathrm{M}$ final concentration) was added to initiate the elongation reaction (Fig. 6a). Representative gel electrophoresis data provided in Fig. $6 \mathrm{~b}$ demonstrate that gp43exo- easily extends beyond both cytosine-2'-deoxyriboside monophosphate (dCMP) and dAMP when paired opposite 8-oxo-G. Surprisingly, the high-fidelity polymerase extends beyond alkylated nucleotides such as $N^{6}$ Me-dATP and $0^{6}$-Me-dGTP but displays difficulty in extending beyond 6-CI-PTP. The difference in extension capabilities could be caused by two distinct mechanisms. The first represents the contributions of shape complementarity, which could explain the ability of gp43 to elongate beyond dCMP paired opposite 8-oxo-G, as this base pair is predicted to resemble a normal Watson-Crick base pair. Likewise, extension beyond $\mathrm{dA}: 8-0 \mathrm{xo}-\mathrm{G}$ can be explained by shape complementarity, assuming that dAMP pairs opposite the oxidized lesion in the syn conformation as predicted in Fig. 5c. Indeed, pairing of the alkylated nucleotides, $N^{6}$-Me-dATP and $O^{6}$-Me-dGTP, opposite the syn conformation of 8-oxo-G would also possess enough shape complementarity to a natural purine:pyrimidine base pair to allow for facile extension. However, the inefficient extension of 6-Cl-PTP suggests that shape complementarity alone does

(a)

13-mer

32P-5'-TCGCAGCCGTCCA 3'-AGCGTCGGCAGGT X्XACCAAA-5'

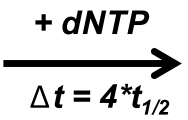

32P-5'-TCGCAGCCGTCCAN 3'-AGCGTCGGCAGGT X्XACCAAA-5'

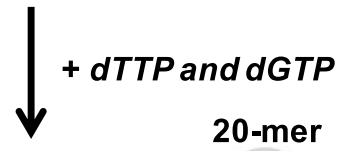

${ }^{32} \mathrm{P}-5$ '-TCGCAGCCGTCCANTGGTTT 3'-AGCGTCGGCAGGT X्XACCAAA-5'

(b)

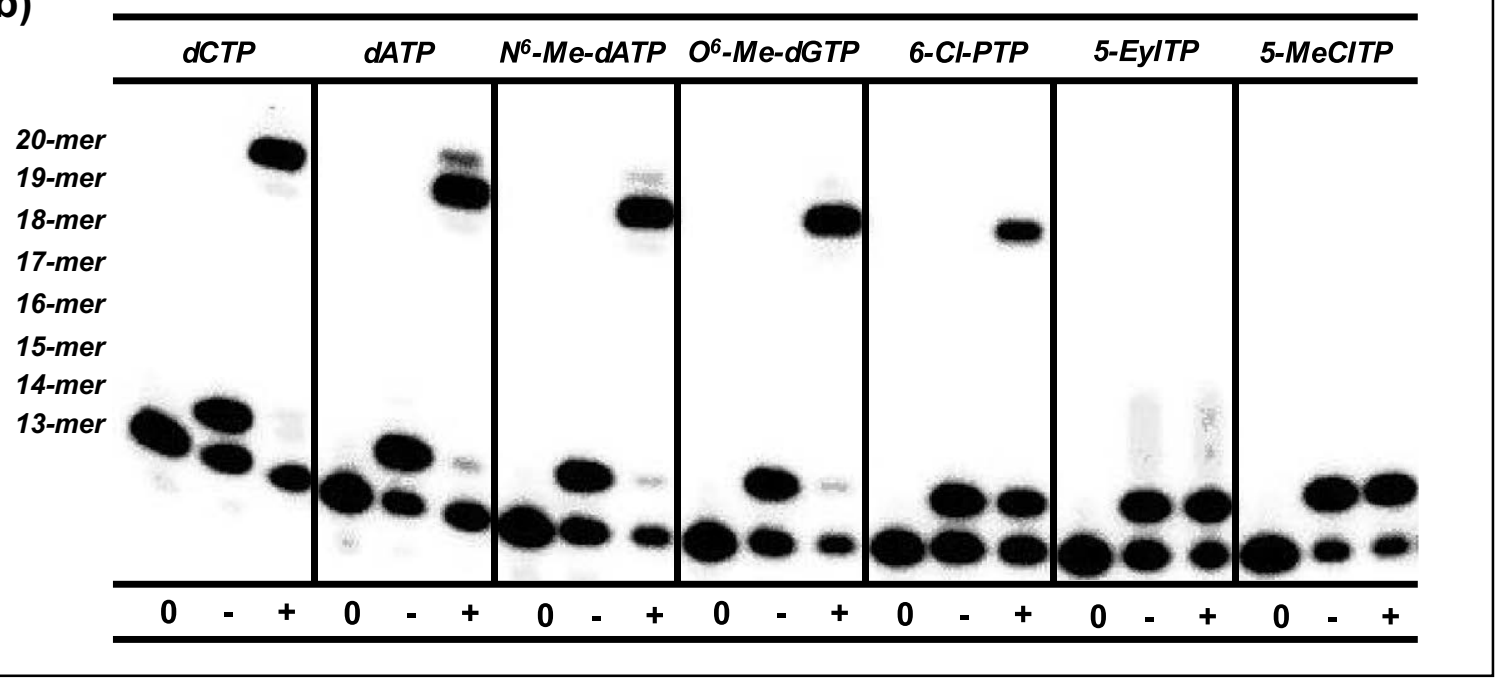

Fig. 6. (a) Assay protocol used to measure extension beyond modified and non-natural nucleotides when inserted opposite 8-oxo-G. (b) Denaturing gel electrophoresis image comparing the incorporation and extension of nucleotide analogs beyond 8-oxo-G by gp43exo- ${ }^{-}$See text for complete details. 
not control elongation beyond mispairs containing 8-oxo-G. This is evident as the surface area and volume of 6-Cl-PTP are both nearly identical to that of dATP (Table 2). In fact, the only difference between the natural nucleotide and 6-Cl-PTP is the replacement of the hydrogen-bonding $-\mathrm{NH}_{2}$ group with a non-hydrogen-bonding halogen. In addition, gp43exo- fails to elongate beyond artificial nucleotide analogs that lack conventional hydrogen-bonding groups such as 5-EyITP and 5-MeCITP. As before, shape complementarity does not directly influence extension capabilities, since 5-EyITP, which is nonextendable, is nearly the same as $N^{6}-\mathrm{Me}-\mathrm{dATP}$, which is efficiently elongated. Collectively, these data suggest that the absence of a hydrogen-bonding group has a detrimental effect on the ability of the high-fidelity polymerase to elongate DNA.

\section{Discussion}

TLS is an essential biological process that allows both prokaryotic and eukaryotic cells to cope with unrepaired DNA lesions. While it is clear that TLS is important for maintaining cell viability, the molecular mechanisms accounting for how certain DNA polymerases efficiently replicate different forms of damaged DNA still remain enigmatic. This study addresses this question by quantitatively comparing the ability of a high-fidelity DNA polymerase to replicate miscoding versus non-instructional DNA lesions. The results from these studies provide a new model highlighting the role of nucleobase hydrophobicity during the replication of structurally distinct DNA lesions. In addition, these analyses provide insight into how nucleobase desoIvation is used differentially by high-fidelity and specialized DNA polymerases and how these differences provide a viable explanation as to why specialized DNA polymerases are more efficient at TLS compared to high-fidelity polymerases. Finally, the results of this study also demonstrate that inappropriate modifications to nucleotide pools can enhance pro-mutagenic DNA synthesis catalyzed by high-fidelity DNA polymerases. By inference, this activity may facilitate the initiation of genetic diseases, the most notable of which is cancer.

While the studies described here have focused on defining how a high-fidelity DNA polymerase replicates damaged DNA, an important question remains as to the activity of specialized DNA polymerases during the replication of 8-oxo-G. Indeed, we previously demonstrated that pol eta relies heavily on hydrogen-bonding interactions when replicating 8-oxo-G [37]. As discussed below, this current study shows that the high-fidelity DNA polymerase, gp43, relies extensively on nucleobase desolvation to efficiently replicate the oxidized DNA lesion. This dichotomy suggests that high-fidelity and specialized DNA polymerases use different molecular forces to replicate damaged DNA. We are currently examining the ability of other specialized DNA polymerase such as human pol iota and pol kappa to utilize these modified nucleotide substrates to provide additional insight into the molecular mechanism(s) of TLS. However, our discussions below first address if a unified mechanism exists that accounts for the ability of high-fidelity DNA polymerases to replicate structurally distinct DNA lesions.

Does a universal mechanism for TLS exist? Our previous studies using the bacteriophage T4 DNA polymerase generated the model provided in Fig. 7 that quantifies the molecular forces influencing key steps in the polymerization pathway during the replication of a non-instructional versus miscoding DNA lesion. Results from this current study recapitulate the importance of nucleobase desolvation toward achieving optimal binding of a nucleotide opposite damaged DNA. In most biological systems, substrate desolvation is a significant barrier in achieving optimal binding and catalysis, since most enzymes rely heavily on the formation of hydrogen-bonding interactions between a substrate and enzyme. This barrier, termed "enthalpic-entropic compensation", occurs as hydrogen bonds that exist in solution between water and a substrate must be removed so that new hydrogen bonds can form between the substrate and amino acids within the enzyme's active site. During DNA polymerization, this barrier is especially relevant, as water molecules must be removed from the incoming nucleotide in order for the DNA polymerase to consummate the formation of correct hydrogen bonds between complementary base pairs within duplex DNA. The kinetic data presented here strengthen this model, as hydrophobic nucleotides bind to gp43 with lower $K_{\mathrm{d}}$ values compared to their unmodified counterparts. In particular, analogs with low solvation energies such $N^{6}$-Me-dATP, $O^{6}$-Me-dGTP, and 6-Cl-PTP bind 3- to 10-fold more tightly than dATP, which has a significantly higher solvation energy. Similar results were obtained with artificial nucleotide analogs such as 5-MeCITP during the replication of non-instructional and miscoding DNA lesions. For example, 5-MeCITP binds with low $K_{d}$ values of $13 \mu \mathrm{M}$ and $57 \mu \mathrm{M}$ during the replication of an abasic site and 8-oxo-G, respectively [29]. The importance of nucleobase desolavtion is further strengthened by weaker binding affinities measured for hydrophilic nucleotide analogs such as 5-CITP, which displays a high $K_{d}$ value of $172 \mu \mathrm{M}$ during the replication of an abasic site [29]. In this case, the high $K_{d}$ value likely reflects an enthalpic penalty caused by the negative charge of the carboxyl group.

While desolvation appears to play a universal role in the binding of the nucleotide substrate during TLS, the molecular forces regulating the polymerization step are more divergent as they depend upon the physical nature of the DNA lesion. For instance, $\pi$-stacking interactions play a large role in facilitating 


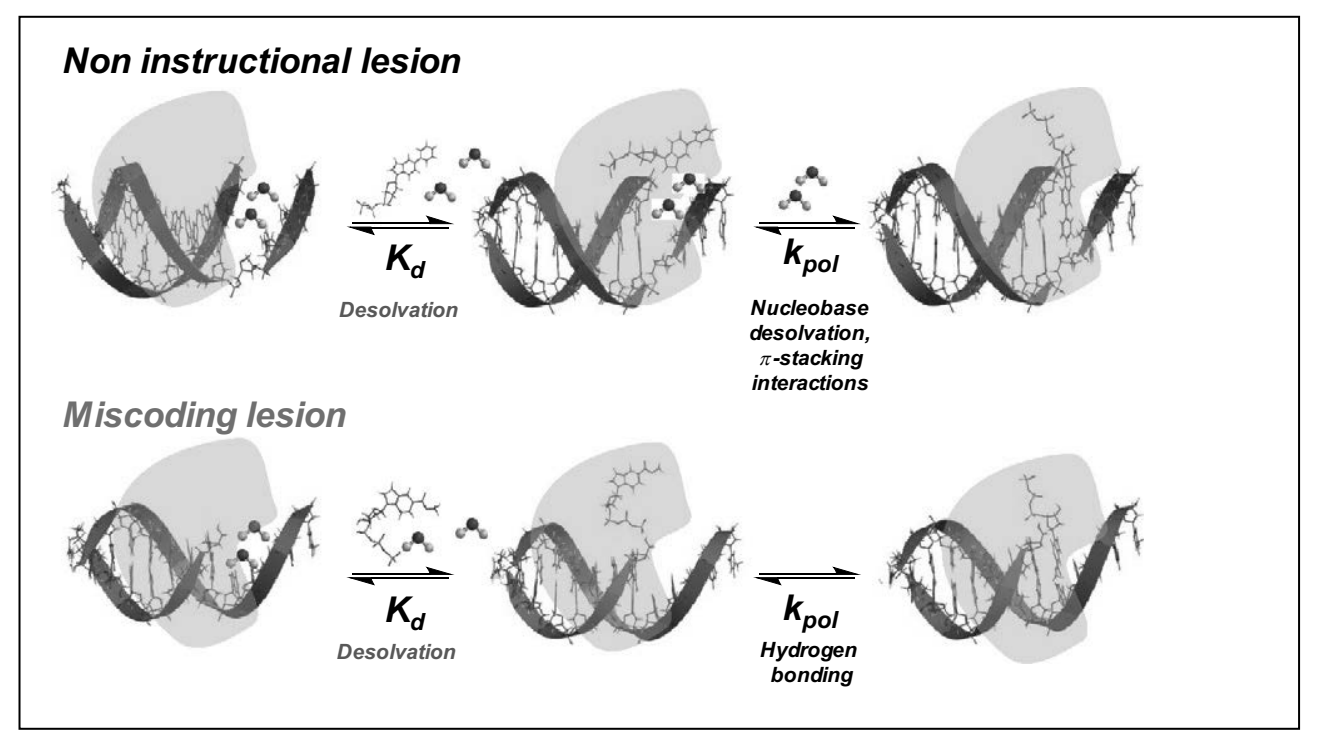

Fig. 7. Model comparing the molecular forces used by gp43 to replicate non-instructional versus miscoding DNA lesions. During the replication of either type of DNA lesion, the nucleotide binding step is controlled by nucleobase desolvation. In contrast, the conformational change step that precedes phosphoryl transfer is regulated by different molecular forces. During the replication of non-instructional lesions such as an abasic site, m-electron density is the preeminent force associated with this kinetic step. During the replication of miscoding lesions such as 8-ox-G, hydrogen-bonding interactions appear to play a more important role in facilitating the conformational change step needed for chemistry to occur.

the polymerization step during the replication of non-instructional lesions such as abasic sites. This is based on the fact that artificial analogs such as 5-CITP and 5-MeCITP that possess significant $\pi$-electron density also display incredibly fast $k_{\text {pol }}$ values of $67 \mathrm{~s}^{-1}$ and $79 \mathrm{~s}^{-1}$, respectively. In contrast, the rate constant for the polymerization step during the replication of the miscoding lesion, 8-oxo-G, depends more upon hydrogen-bonding interactions. This is evident as all of the nucleotide analogs tested here, which contain modifications to hydrogen-bonding groups, have lower $k_{\text {pol }}$ values compared to dATP. In fact, artificial analogs such as 5-CITP and 5-MeCITP that are incorporated opposite an abasic site with fast $k_{\mathrm{pol}}$ values of $\sim 70 \mathrm{~s}^{-1}$ are inserted opposite 8-oxo-G with lower $k_{\text {pol }}$ values of $\sim 0.23 \mathrm{~s}^{-1}$.

Do other DNA polymerases utilize nucleobase desolvation during TLS? During chromosomal replication, high-fidelity DNA polymerases accurately and efficiently replicate undamaged DNA. In contrast, the activity of these DNA polymerases is significantly hindered when replicating damaged DNA. As a result, specialized DNA polymerases such as pol eta, pol kappa, and pol iota are recruited to participate more intimately in the efficient replication of unrepaired DNA lesions. However, the ability of specialized DNA polymerases to effectively perform TLS comes at a cost as they generally display reduced fidelity when replicating undamaged DNA. Current models attempting to explain this dichotomy are based primarily on structural differences that exist between the two classes of DNA polymerase [40-42]. In general, both high-fidelity and specialized DNA polymerases possess a similar global architecture that resembles a right hand and contains elements corresponding to fingers, palm, and thumb domains $[43,44]$. However, close inspection reveals that the active sites of most specialized DNA polymerases are significantly larger than those of high-fidelity DNA polymerases. The expanded active site of specialized DNA polymerases is often used to explain how these polymerases can replicate large, bulky lesions, whereas the more constrained active site of high-fidelity polymerases hinders their ability to efficiently replicate damaged DNA. At face value, the results presented here using modified nucleotide analogs are consistent with the mechanism. However, we propose that nucleobase solvation also plays an important role in achieving nucleotide discrimination, especially during the replication of damaged DNA. An excellent example of this phenomenon comes from the kinetic studies here demonstrating that gp 43 binds dATP very poorly when replicating 8-oxo-G. In this case, we propose that the weaker binding affinity reflects energetic penalties associated with stripping away water molecules that are bound to key hydrogen-bonding groups present on the natural nucleotide. The inference here is that the association of water molecules with these functional groups creates a solvation sphere around the nucleobase, which increases the overall size of the nucleotide. The resulting increase in size hinders efficient binding within the constrained active sites 
of high-fidelity polymerases. As demonstrated here, modifications such as alkylation that increase the overall hydrophobicity of the nucleobase also reduce the size of this solvation sphere. The biophysical consequence is that the smaller size of the nucleotide makes binding to the polymerase more efficient and lowers the energetic penalties required for complete desolvation of the incoming nucleotide.

In the case of high-fidelity polymerases, we propose that water is used to achieve negative selection against nucleotide binding. With specialized DNA polymerases, we propose that nucleobase desolvation plays a different yet important role in allowing these enzymes to replicate damaged DNA. In this model, specialized DNA polymerases use enthalpicentropic compensation as a way to generate high catalytic efficiency during TLS. This is possible as the expanded active site of a specialized DNA polymerase is large enough to bind a fully solvated nucleotide. This essentially bypasses the initial requirement for nucleobase desolvation. Consistent with this mechanism are previous data obtained using the specialized DNA polymerase, pol $\eta$, in which the $K_{m}$ values measured for modified and artificial nucleotides were independent of their hydrophilic or hydrophobic nature [37]. For instance, the $K_{\mathrm{m}}$ for dATP is $47 \mu \mathrm{M}$, while the $K_{\mathrm{m}}$ values for hydrophobic analogs such as $N^{6}$-Me-dATP, $O^{6}$-Me-dGTP, 5-EyITP, and 5-NITP remain invariant at $\sim 50 \mu \mathrm{M}$ [37]. While this mode of binding may seem counterproductive, the ability of specialized DNA polymerases to bind a fully solvated nucleotide could play two important roles in its primary function to replicate damaged DNA. First, water molecules surrounding the incoming nucleobase could move within the active site of the polymerase. This mobility could generate greater flexibility that could subsequently provide these DNA polymerases opportunities to optimize productive interactions between the incoming nucleotide and a DNA lesion. In this model, the greater entropy provided by increased water mobility may allow these polymerases to accommodate a variety of structurally distinct DNA lesions ranging from non-instructional including abasic sites to crosslinked lesions such as thymine dimers and cisplatinated DNA. In addition, the larger solvation sphere could also provide enthlapic stabilization by increasing hydrogen-bonding interactions that are required for interactions between the incoming nucleotide and a DNA lesion. The synergy between these features may account for improved efficiency of specialized polymerases such as pol eta to perform TLS. In addition, this may also explain why certain specialized DNA polymerases display reduced fidelity when replicating undamaged DNA. In this case, the ability of the polymerase to move water molecules within its active site could allow the polymerase to form mispairs more easily. While the kinetic studies described here provide initial evidence redefining the role of nucleobase desolvation during replication, we acknowledge that more experimentation is needed to fully quantify this biophysical feature during normal and translesion DNA synthesis. Toward this goal, we are currently examining the effects of molecular crowding agents and solvent isotope effects to further explore the role of nucleobase desolvation by both high-fidelity and specialized DNA polymerases.

\section{Material and Methods}

\section{Materials}

[Y- $\left.{ }^{32} \mathrm{P}-\mathrm{ATP}\right]$ was purchased from MP Biomedicals. $\mathrm{Mg}(\mathrm{OAc})_{2}$ and Trizma buffer were purchased from Sigma. Oligonucleotides containing $\mathrm{G}$ and 8-oxo-G at the 14th position were synthesized by Operon and purified as previously described [37]. Modified purine nucleotides including dATP, dGTP, $N^{6}-\mathrm{Me}-$ dATP, 6-Cl-dATP, 6-Cl-2APTP, O-Me-dGTP, $N^{2}$ Me-dGTP, 2,6-diaminopurine-2'-deoxyriboside-5'triphosphate, and dITP were purchased from Trilink Biotechnologies (San Diego, CA). We synthesized and purified 5-substituted indolyl nucleotides including indolyl-2'-deoxyriboside triphosphate, 5-MelTP, 5-EtITP, 5-EyITP, 5-NITP, and 5-MeCITP as previously described [27-29]. All nucleotides were $>99 \%$ pure. All other materials were obtained from commercial sources at the highest standards for purity. Exonuclease-deficient T4 DNA polymerase (D129A gp43exo ${ }^{-}$) was purified and quantified as previously described [45].

\section{Polymerization assays}

All kinetic assays were performed at $25^{\circ} \mathrm{C}$. The buffers used in all assays consisted of $25 \mathrm{mM}$ Tris-OAc (pH 7.5), $150 \mathrm{mM} \mathrm{KOAc}$, and $10 \mathrm{mM}$ 2-mercaptoethanol. The amount of product formed in the polymerization reactions was monitored through analysis on $20 \%$ sequencing gels [24]. Gel images were obtained using a Packard Phosphorlmager and Optiquant software supplied by the manufacturer. The amount of product formed was quantified by measuring the ratio of ${ }^{32} \mathrm{P}$-labeled extended to non-extended primer. Obtained ratios were corrected for substrate in the absence of the polymerase (zero point). Corrected ratios of product formation were multiplied by the concentration of primer/template used in each assay to yield total amount of product.

\section{Single turnover nucleotide incorporation assays}

gp43exo- $(200 \mathrm{nM})$ was incubated with $100 \mathrm{nM}$ DNA $\left(13 / 20_{G}\right.$ or $\left.13 / 20_{8-o x o-G}\right)$ in $1 X$ assay buffer and $10 \mathrm{mM} \mathrm{Mg}(\mathrm{OAc})_{2}$. The polymerization reaction was initiated through the addition of dNTP at 
concentrations ranging from 0.005 to $1 \mathrm{mM}$. Reactions were quenched with $200 \mathrm{mM}$ EDTA at variable times (5-600 s). Data obtained for single turnover time courses were fit to Eq. (1).

$y=A\left(1-e^{-k t}\right)+C$

where $A$ is the amplitude of product formation, $k$ is the observed rate constant in product formation, $t$ is time, and $C$ is a defined constant. The data for the dependency of $k_{\text {obs }}$ on dNTP concentration were fit to the Michaelis-Menten equation [Eq. (2)]:

$k_{\mathrm{obs}}=k_{\mathrm{pol}}[\mathrm{dNTP}] /\left(K_{\mathrm{d}}+[\mathrm{dNTP}]\right)$

where $k_{\text {obs }}$ is the observed rate constant, $k_{\text {pol }}$ is the maximal polymerization rate constant, $K_{d}$ is the dissociation constant for dNTP, and dNTP is the concentration of the modified or non-natural nucleotide substrate.

\section{Inhibition studies}

We incubated $100 \mathrm{nM}$ 13/20 8 -oxo-G with $10 \mathrm{mM}$ $\mathrm{Mg}(\mathrm{OAc})_{2}, 50 \mu \mathrm{M}$ dATP, and variable concentrations of $N^{2}$-Me-dGTP $(0-200 \mu \mathrm{M})$. Polymerization reactions were initiated through the addition of $200 \mathrm{nM} \mathrm{gp} 4 \mathrm{exo}^{-}$. Reactions were quenched through the addition of $200 \mathrm{mM}$ EDTA at variable times (5-180 s) and analyzed as described above. Data were fit to Eq. (1), which defines a singleexponential process. Rate constants $\left(k_{\text {obs }}\right)$ were plotted versus the concentration of $N^{2}$-Me-dGTP and fit using non-linear regression analysis [Eq. (3)] to obtain an apparent $K_{\mathrm{i}}$ value $\left(K_{\mathrm{i}}\right.$ app):

$$
k_{\mathrm{obs}}=k_{\mathrm{obs} \max }\left(1-\left(\left[N^{2}-\mathrm{Me}-\mathrm{dGTP}\right] /\left(\left[N^{2}-\mathrm{Me}-\mathrm{dGTP}\right]+K_{\mathrm{i} \text { app }}\right)\right)\right.
$$

where $k_{\text {obs }}$ is the observed rate constant, $k_{\text {obs max }}$ is the rate constant obtained in the absence of $N^{2}$-MedGTP, [ $N^{2}$-Me-dGTP] is the concentration of nucleotide inhibitor, and $K_{\mathrm{i}}$ app is the apparent inhibition constant for $N^{2}$-Me-dGTP.

A true $K_{\mathrm{i}}$ value was obtained using Eq. (4):

$K_{i}=K_{\mathrm{i} \text { app }} /\left(1+\left(\mathrm{S} / K_{m}\right)\right)$

where $K_{\mathrm{i}}$ is the true inhibition constant, $K_{\mathrm{i}}$ app is the apparent inhibition constant, $S$ is the concentration of the substrate, dATP, and $K_{\mathrm{m}}$ is the Michaelis constant for dATP.

\section{Pulse chase experiments}

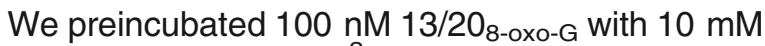
$\mathrm{Mg}(\mathrm{OAc})_{2}$ and $60 \mu \mathrm{M} \mathrm{N} N^{2}$-Me-dGTP. Then, $200 \mathrm{nM}$ gp43exo ${ }^{-}$was added, followed by the addition of $250 \mu \mathrm{M} \mathrm{dATP}$ at variable time points (0.5-20 $\mathrm{min})$. The reaction mixture was quenched with $500 \mathrm{mM}$ EDTA at time intervals ranging from 5 to $180 \mathrm{~s}$, and the amount of product formed by the incorporation of dATP was analyzed as described above. The amplitudes in product formation at these differential time points were plotted versus time of dATP addition. The resulting plot was linear and fit to the equation for a straight line [Eq. (5)]:

$y=m x+b$

where $m$ is the slope of the line, $b$ is the $y$-intercept, and $t$ is time.

\section{Extension beyond 8-0xo-G}

Assays were performed using single turnover reaction conditions in order to maximize signal-tonoise ratios in product formation. Under these conditions, an excess concentration of gp43exo $(200 \mathrm{nM})$ was incubated with $100 \mathrm{nM} 13 / 20_{8-o x o-G}$ in assay buffer containing $10 \mathrm{mM}$ magnesium acetate and then mixed with a fixed concentration of nucleotide (dNTP) and $5 \mathrm{mM} \mathrm{Mg}(\mathrm{OAc})_{2}$ to initiate insertion opposite the lesion. After four half-lives, an aliquot of dTTP and dGTP $(200 \mu \mathrm{M}$ final concentration) was added to initiate the elongation reaction. Aliquots of the reactions were quenched with EDTA at variable times (0-600 s) and analyzed by denaturing gel electrophoresis to assess elongation.

\section{Molecular modeling studies}

Since no complete $\mathrm{x}$-ray or NMR structures are available for the bacteriophage T4 DNA polymerase, structural models of the RB69 DNA polymerase were used as a surrogate for the T4 DNA polymerase. The RB69 DNA polymerase is structurally and functionally homologous to T4 DNA polymerase [46]. Models of the polymerase in complex with DNA containing 8-oxo-G were obtained from the Research Collaboratory for Structural Bioinformatics Protein Data Bank ${ }^{\dagger}$. The structural models of RB69 containing DNA ${ }_{8-0 x o-G^{-}}$ dNTP complex were made from the co-crystal structure of RB 69-DNA 8 -oxo-G-dATP/dCTP (PDB ID: $3 \mathrm{LDS} / 3 \mathrm{NC1}$ ) $[47,48]$.

Using the molecular modeling program Molecular Operating Environment, structures containing the analogs $N^{2}$-Me-dGMP and 5-Me-CIMP were generated by modifying dAMP in the crystal structure (PDB ID: 3LDS). Following the modifications, the active site of RB69 was minimized using the MOE modeling software (MOE 2014). The modeling program Chimera was used to generate modified 
RB69-DNA 8-Oxo-G- $N^{2}$-Me-GMP/5-MeCIMP complexes to determine interglycosyl distances between base pairs in addition to distances between templating bases and active amino residues. Hydrophobicity surface models were generated for the polymerase containing DNA-dNTP complex using Kyle Doolittle hydrophobicity scale. The scale of hydrophobicity is represented in decreasing order as red $>$ white $>$ blue.

\section{Acknowledgments}

The authors wish to thank Dr. Jung-Suk Choi for helpful discussions and critical reading of this manuscript. Research was funded by the Department of Defense (W81XWH-13-1-0238) to A.J.B. and a Dissertation Research Award (0010-1710-10 DDDSARI) provided by Cleveland State University to A.D.

Received 22 March 2017;

Received in revised form 1 June 2017;

Accepted 1 June 2017

Available online 7 June 2017

\author{
Keywords: \\ mutagenesis; \\ DNA polymerases; \\ oxidative stress; \\ translesion DNA synthesis; \\ nucleoside analogs
}

$\dagger w w w . p d b . o r g$

\section{Abbreviations used:}

8-oxo-G, 8-oxo-guanine; DSB, double-strand DNA break; TLS, translesion DNA synthesis; $N^{6}$-Me-dATP, $N^{6}$-methyl-adenosine-2'-deoxyriboside triphosphate; dGTP, guanosine-2'-deoxyriboside triphosphate; 5-NITP, 5-nitro-indolyl-2'-deoxyriboside triphosphate; dAMP, adenosine-2'-deoxyriboside monophosphate; dNTP, deoxynucleoside triphosphate; G, guanine; dATP, adenosine2'-deoxyriboside triphosphate; $O^{6}$-Me-dGTP, $O^{6}$-methylguanosine-2'-deoxyriboside triphosphate; $N^{2}$-Me-dGTP, $N^{2}$-methyl-guanosine-2'-deoxyriboside triphosphate; 6-Cl-dATP, 6-chloropurine-2'-deoxyadenosine5'-triphosphate; 6-Cl-2APTP, 6-chloro-2-amino-2'deoxyriboside-5'-triphosphate; dITP, 2'-deoxyinosine-5' triphosphate; 5-MeCITP, 5-methylcarboxyl-indolyl-2'deoxyriboside triphosphate; 5-MeITP, 5-methy-lindolyl-2'deoxyriboside triphosphate; 5-EtITP, 5-ethyl-indolyl-2'deoxyriboside triphosphate; 5-EylTP, 5-ethyleneindolyl-2'-deoxyriboside triphosphate; 5-CITP, 5-carboxylindolyl-2'-deoxyriboside triphosphate; dCMP, cytosine-2'deoxyriboside monophosphate.

\section{References}

[1] M.F. Goodman, K.D. Fygenson, DNA polymerase fidelity: from genetics toward a biochemical understanding, Genetics 148 (1998) 1475-1482.

[2] T.A. Kunkel, K. Bebenek, DNA replication fidelity, Annu. Rev. Biochem. 69 (2000) 497-529.

[3] T.L. Capson, J.A. Peliska, B.F. Kaboord, M.W. Frey, C. Lively, M. Dahlberg, S.J. Benkovic, Kinetic characterization of the polymerase and exonuclease activities of the gene 43 protein of bacteriophage T4, Biochemistry 31 (1992) 10,984-10,994.

[4] H. Echols, M.F. Goodman, Fidelity mechanisms in DNA replication, Annu. Rev. Biochem. 60 (1991) 477-511.

[5] M.F. Goodman, S. Creighton, L.B. Bloom, J. Petruska, Biochemical basis of DNA replication fidelity, Crit. Rev. Biochem. Mol. Biol. 28 (1993) 83-126.

[6] E.T. Kool, Hydrogen bonding, base stacking, and steric effects in DNA replication, Annu. Rev. Biophys. Biomol. Struct. 30 (2001) 1-22.

[7] C. Lengauer, K.W. Kinzler, B. Vogelstein, Genetic instabilities in human cancers, Nature 396 (1998) 643-649.

[8] Y. Nakabeppu, K. Sakumi, K. Sakamoto, D. Tsuchimoto, T. Tsuzuki, Y. Nakatsu, Mutagenesis and carcinogenesis caused by the oxidation of nucleic acids, Biol. Chem. 387 (2006) 373-379.

[9] L.A. Loeb, Mutator phenotype in cancer: origin and consequences, Semin. Cancer Biol. 20 (2010) 279-280.

[10] A.L. Millen, P. Sharma, S.D. Wetmore, C8-linked bulky guanosine DNA adducts: experimental and computational insights into adduct conformational preferences and resulting mutagenicity, Future Med. Chem. 4 (2012) 1981-2007.

[11] N.R. Jena, P.C. Mishra, Formation of ring-opened and rearranged products of guanine: mechanisms and biological significance, Free Radic. Biol. Med. 53 (2012) 81-94.

[12] S. Boiteux, M. Guillet, Abasic sites in DNA: repair and biological consequences in Saccharomyces cerevisiae, DNA Repair (Amst) 3 (2004) 1-12.

[13] W.P. Roos, A.D. Thomas, B. Kaina, DNA damage and the balance between survival and death in cancer biology, Nat. Rev. Cancer 16 (2016) 20-33.

[14] E. Freisinger, A.P. Grollman, H. Miller, C. Kisker, Lesion (in)tolerance reveals insights into DNA replication fidelity, EMBO J. 23 (2004) 1494-1505.

[15] A.C. Klarer, W. McGregor, Replication of damaged genomes, Crit. Rev. Eukaryot. Gene Expr. 21 (2011) 323-336.

[16] M.F. Goodman, Better living with hyper-mutation, Environ. Mol. Mutagen. 57 (2016) 421-434.

[17] L. Guan, K. Bebenek, T.A. Kunkel, M.M. Greenberg, Inhibition of short patch and long patch base excision repair by an oxidized abasic site, Biochemistry 49 (2010) 9904-9910.

[18] G. Maga, B. van Loon, E. Crespan, G. Villani, U. Hübscher, The block of DNA polymerase delta strand displacement activity by an abasic site can be rescued by the concerted action of DNA polymerase beta and Flap endonuclease 1, J. Biol. Chem. 284 (2009) 14,267-14,275.

[19] A. Maor-Shoshani, K. Hayashi, H. Ohmori, Z. Livneh, Analysis of translesion replication across an abasic site by DNA polymerase IV of Escherichia coli, DNA Repair (Amst) 2 (2003) 1227-1238.

[20] H. Ling, F. Boudsocq, R. Woodgate, W. Yang, Snapshots of replication through an abasic lesion; structural basis for base substitutions and frameshifts, Mol. Cell 13 (2004) 751-762. 
[21] M. Hogg, S.S. Wallace, S. Doublié, Crystallographic snapshots of a replicative DNA polymerase encountering an abasic site, EMBO J. 23 (2004) 1483-1493.

[22] X. Zhong, L.C. Pedersen, T.A. Kunkel, Characterization of a replicative DNA polymerase mutant with reduced fidelity and increased translesion synthesis capacity, Nucleic Acids Res. 36 (2008) 3892-3904.

[23] J.S. Taylor, New structural and mechanistic insight into the A-rule and the instructional and non-instructional behavior of DNA photoproducts and other lesions, Mutat. Res. 510 (2002) 55-70.

[24] A.J. Berdis, Dynamics of translesion DNA synthesis catalyzed by the bacteriophage T4 exonuclease-deficient DNA polymerase, Biochemistry 40 (2001) 7180-7191.

[25] B. Devadoss, I. Lee, A.J. Berdis, Enhancing the "A-rule" of translesion DNA synthesis: promutagenic DNA synthesis using modified nucleoside triphosphates, Biochemistry 46 (2007) 13,752-13,761.

[26] E.Z. Reineks, A.J. Berdis, Evaluating the contribution of base stacking during translesion DNA replication, Biochemistry 43 (2004) 393-404.

[27] X. Zhang, I. Lee, A.J. Berdis, Evaluating the contributions of desolvation and base-stacking during translesion DNA synthesis, Org. Biomol. Chem. 2 (2004) 1703-1711.

[28] X. Zhang, I. Lee, X. Zhou, A.J. Berdis, Hydrophobicity, shape, and pi-electron contributions during translesion DNA synthesis, J. Am. Chem. Soc. 128 (2006) 143-149.

[29] E.A. Motea, I. Lee, A.J. Berdis, Quantifying the energetic contributions of desolvation and $\pi$-electron density during translesion DNA synthesis, Nucleic Acids Res. 39 (2011) 1623-1637.

[30] E.A. Motea, I. Lee, A.J. Berdis, Insights into the roles of desolvation and $\pi$-electron interactions during DNA polymerization, Chembiochem 14 (2013) 489-498.

[31] H.J. Einolf, F.P. Guengerich, Fidelity of nucleotide insertion at 8-oxo-7,8-dihydroguanine by mammalian DNA polymerase delta. Steady-state and pre-steady-state kinetic analysis, J. Biol. Chem. 276 (2001) 3764-3771.

[32] M. Hori, S. Yonekura, T. Nohmi, P. Gruz, H. Sugiyama, S. Yonei, Q.M. Zhang-Akiyama, Error-prone translesion DNA synthesis by Escherichia coli DNA polymerase IV (DinB) on templates containing 1,2-dihydro-2-oxoadenine, J. Nucleic Acids 2010 (2010) 807,579.

[33] S. Avkin, Z. Livneh, Efficiency, specificity and DNA polymerasedependence of translesion replication across the oxidative DNA lesion 8-oxoguanine in human cells, Mutat. Res. 510 (2002) 81-90.

[34] H.J. Einolf, N. Schnetz-Boutaud, F.P. Guengerich, Steadystate and pre-steady-state kinetic analysis of 8-0xo-7,8- dihydroguanosine triphosphate incorporation and extension by replicative and repair DNA polymerases, Biochemistry 37 (1998) 13,300-13,312.

[35] J.W. Hanes, D.M. Thal, K.A. Johnson, Incorporation and replication of 8-oxo-deoxyguanosine by the human mitochondrial DNA polymerase, J. Biol. Chem. 281 (2006) 36,241-36,248.

[36] D. Chavarria, A. Ramos-Serrano, I. Hirao, A.J. Berdis, Exploring the roles of nucleobase desolvation and shape complementarity during the misreplication of $O^{6}$-methylguanine, J. Mol. Biol. 412 (2011) 325-339.

[37] J.-S. Choi, A. Dasari, P. Hu, S.J. Benkovic, A.J. Berdis, The use of modified and non-natural nucleotides provide unique insights into pro-mutagenic replication catalyzed by polymerase eta, Nucleic Acids Res. 44 (2016) 1022-1035.

[38] R. Perozzo, G. Folkers, L. Scapozza, Thermodynamics of protein-ligand interactions: history, presence, and future aspects, J. Recept. Signal Transduct. Res. 24 (2004) 1-52.

[39] C. Bissantz, B. Kuhn, M. Stahl, A medicinal chemist's guide to molecular interactions, J. Med. Chem. 53 (2010) 5061-5084.

[40] E.T. Kool, Active site tightness and substrate fit in DNA replication, Annu. Rev. Biochem. 71 (2002) 191-219.

[41] W. Yang, Portraits of a Y-family DNA polymerase, FEBS Lett. 579 (2005) 868-872.

[42] W. Yang, An overview of Y-family DNA polymerases and a case study of human DNA polymerase $\eta$, Biochemistry 53 (2014) 2793-2803.

[43] T. Steitz, DNA polymerases: structural diversity and common mechanisms, J. Biol. Chem. 274 (1999) 17,395-17,398.

[44] C.A. Brautigam, T.A. Steitz, Structural and functional insights provided by crystal structures of DNA polymerases and their substrate complexes, Curr. Opin. Struct. Biol. 8 (1998) 54-63.

[45] M.W. Frey, N.G. Nossal, T.L. Capson, S.J. Benkovic, Construction and characterization of a bacteriophage T4 DNA polymerase deficient in $3^{\prime}->5^{\prime}$ exonuclease activity, Proc. Natl. Acad. Sci. U. S. A. 90 (1993) 2579-2583.

[46] D.K. Braithwaite, J. Ito, Compilation, alignment, and phylogenetic relationships of DNA polymerases, Nucleic Acids Res. 21 (1993) 787-802.

[47] M. Hogg, J. Rudnicki, J. Midkiff, L. Reha-Krantz, S. Doublié, S.S. Wallace, Kinetics of mismatch formation opposite lesions by the replicative DNA polymerase from bacteriophage RB69, Biochemistry 49 (2010) 2317-2325.

[48] J. Wang, A.K. Sattar, C.C. Wang, J.D. Karam, W.H. Konigsberg, T.A. Steitz, Crystal structure of a pol alpha family replication DNA polymerase from bacteriophage RB69, Cell 89 (1997) 1087-1099. 